\title{
Early Detection and Education of Potential Obesity for Prospective Brides Using an Android-Based Botting Macca Application
}

\author{
Risa Arieska ${ }^{1}$ Syafruddin Syarif ${ }^{2} \quad$ Andi Nilawati Usman ${ }^{3}$ \\ 1.Department of Midwifery, Graduate School, Hasanuddin University, Indonesia \\ 2.Electrical Engineering Study Program, Faculty of Engineering, Hasanuddin University, Indonesia \\ 3.Department of Obstetrics and Gynecology, Hasanuddin University, Indonesia
}

\begin{abstract}
Non-communicable diseases related to being overweight or obese have become a worldwide problem. There are various ways to help the weight loss program. This research aims to develop an android-based application for early detection and education of potential obesity for prospective brides, to test validation of media and material experts on products, small and large sample trials with a pre-post test on prospective brides. This study is categorized as research and development (R\&D) based on Borg and Gall development model. Quasi-experimental design with a pre-post test was used in the research. Purposive sampling was used with 20 respondents of the prospective bride who were given an android-based application and 20 respondents were given print media. The research was conducted in Makassar, South Sulawesi in January - July 2020. The final results were carried out by the ManWhitney statistical test to see the effect of giving applications to the prospective bride. The results of the research obtained the Botting Macca application was feasible to be developed based on the assessment of the media and material expert validation tests, and the results of small sample trials. The results of the large sample trial obtained p-value $0.001<p$ value 0.05 meaning that the Botting Macca application affects early detection and education of potential obesity in the prospective bride. The research implies an Android-based of Botting Macca application program is applicable and suitable for future use.
\end{abstract}

Keywords: Applications, Android, Media, Obesity, Print Out

DOI: $10.7176 /$ ALST/82-03

Publication date:October $31^{\text {st }} 2020$

\section{Introduction}

Obesity and overweight play a big role in the increase of morbidity and mortality worldwide (Wang et al. 2016); Sebastian, 2020). The prevalence of overweight and obesity has globally increased. Adults increased by $2.75 \%$, children by $47.1 \%$, men by $13.9 \%$ lower than women by $23.8 \%$, urban areas by $23.8 \%$, and rural areas by $16.3 \%$ from 1980 to 2013. This number continued to increase from 921 million to 2.1 billion (Rosengren et al 2015; Risk and Collaboration 2017).

The proportion of overweight and obesity among adults has increased from year to year in South Sulawesi Province, Indonesia . The proportion of overweight increased by $8.6 \%$ in $2007,11.5 \%$ in 2013 , and $2.1 \%$ in 2018 (Pujilestari et al 2019). Meanwhile, the proportion of obesity raised from $10.5 \%$ to $14.8 \%$ in 2013 and $7.0 \%$ in 2018 (Pengpid and Peltzer 2017).

Some factors cause overweight and obesity including genetic factors, food choices, eating habits, food portions, environment, and lack of physical activity (Pengpid and Peltzer 2016). Obesity can increase the risk of various health problems such as asthma, diabetes mellitus types 1 and 2, cardiovascular disorders, hypertension, sleep disorders, bone disorders, hormonal disorders, and sexual disorders (Pegington, French, and Harvie, 2020; Nurwanti et al., 2018). Besides, overweight and obesity are the risk factors for infertility (Mooyaart, Liefbroer, and Billari, 2019; Leech and Johnson, 2012).

Several research programs related to the problem of overweight and obesity have been carried out (Ambrosini et al 2018; Hernandez 2020). Traditional use of books or leaflets is considered ineffective and inefficient to implement (Khusun and Fahmida, 2016; Fransen et al 2018; Ambrosini et al 2018). The advance of technology in smartphone and web-based application is expected to give a positive impact on weight loss, behavioral changes in food selection, physical activity, and a good understanding in utilizing the application (Hernandez, 2020; Afshin et al., 2016; Beleigoli et al., 2018; Buchan and Morgan, 2019; Duncan et al., 2018; Dunn et al., 2019; Foley et al., 2016). Furthermore, people understand relatively little about the dangers of overweight and obesity (Hutchesson et al., 2016; Lee and Michaelides, 2017; Matthews et al., 2017). Therefore, the researchers intend to develop an Android-based of Botting Macca application program for early detection and education of potential obesity for prospective brides. 


\section{Methods}

2.1 Study design

This study used Research and Development (R\&D) based on Borg and Gall development model and quasiexperimental pre-post test (Huang et al. 2019). This research method intends to develop or validate products applied in education (Short et al. 2018). The product undergoes a validation test by a media expert, two material experts, and a small $(n=10)$ and large $(n=40)$ sample trial (Amelia et al. 2020).

\subsection{Participants}

The research respondents were prospective brides registered in January - July 2020 at Religious Affairs Office Biringkanaya. Respondents were taken by purposive sampling. The experimental group $(n=20)$ was given Botting Macca Application, and the control group $(\mathrm{n}=20)$ was given print media.

\subsection{Data collection}

The respondents in each group were required to inform their weight, height, and abdominal circumference for early detection as well as underwent monitoring for research activities once a week for 4 weeks.

\subsection{Statistical Data Analysis}

Data were analyzed using small sample trials and questionnaires assessed by the media expert and two material experts while large sample trials used the Man-Whitney test. The average score for each expert's assessment is included in Table 1. If the calculation results show the value of each aspect is in the range $2.51-3.25$ or 3.26 4.00 , it categorizes valid and does not need to be revised.

Table 1. Value ranges and scales

\begin{tabular}{cl}
\hline Very good & $3.26-4.00$ \\
\hline Well & $2.51-3.25$ \\
\hline Enough & $1.76-2.50$ \\
\hline Less & $1.00-1.75$ \\
\hline
\end{tabular}

\subsection{Research Ethics}

The study received a recommendation of ethical approval from the Faculty of Public Health, Hasanuddin Makassar University with protocol number 7420092136.

\section{Result}

\subsection{Android-based of Botingg Macca Application Product}

The name of Botting Mecca was adapted from the traditional language, Buginese, meaning a smart bride. The researchers expect that the application can be useful and give a positive impact on users.

\subsection{Media Expert and Material Expert Validations, and Small Sample Trial}

According to the results of the application feasibility test, it could be concluded that the result of the assessment from the media experts was in a good category with an average score of 3.25 (see Table 2). The assessment included the size of the application, cover design, and application content. Meanwhile, the result of the assessment from the material experts was in a very good category with an average score of 3.30 (see Table 3 ). The assessment consisted of the feasibility of content, presentation, and, language and context. Also, the result of the assessment in the small sample trial was in a very good category with an average score of 3.63 (see Table 4). The assessment is composed of components of interest, content, and language. Based on the above description, the result of the total average score of media experts, material experts, and small sample trials on the Botting Macca Application product was in a very good category with a minimum score of 3.56 . 
Table 2. The results of the media expert's test of the Botting Macca application for early detection and education of potential obesity

\begin{tabular}{|c|c|c|c|}
\hline \multicolumn{2}{|r|}{ ASSESSMENT ASPECT } & MEDIA EXPERT & AVERAGE RATING \\
\hline \multicolumn{2}{|r|}{ Application Size } & 3.5 & 3.5 \\
\hline 1. & Suitability of application size with ISO standards & 3 & \\
\hline 2. & Suitability of size with the content of the application & 4 & \\
\hline \multicolumn{2}{|r|}{ Cover Design } & 3.25 & 3.25 \\
\hline 3. & The appearance of layout elements & 3 & \\
\hline 4. & Color layout elements & 4 & \\
\hline 5. & The letters used are attractive and easy to read & 3 & \\
\hline 6. & Application cover illustration & 3 & \\
\hline \multicolumn{2}{|r|}{ Application Content Design } & 3 & 3 \\
\hline 7. & Consistency of appearance layout & 3 & \\
\hline 8. & Printable and space layout elements & 3 & \\
\hline 9. & Title layout elements and illustrations & 3 & \\
\hline 10 & Embedding layout & 3 & \\
\hline 11 & The typography of simple application contents & 3 & \\
\hline 12 & The typography of the app content is easy to understand & 3 & \\
\hline 13 & Content illustration & 3 & \\
\hline \multicolumn{2}{|r|}{ Average } & 3.25 & 3.25 (Good) \\
\hline
\end{tabular}

Table 3.The results of the material expert's test on the Botting Macca application for early detection and education of potential obesity

\begin{tabular}{|c|c|c|c|}
\hline Component & EXPERT I & EXPERT II & Average rating \\
\hline Content Feasibility Aspects & 3,6 & 2.65 & 3.12 \\
\hline Material feasibility & 4 & 3.5 & \\
\hline Material accuracy & 3,4 & 2,6 & \\
\hline New and advanced materials & 3 & 2.5 & \\
\hline Encourage curiosity & 4 & 2 & \\
\hline Presentation Feasibility Aspects & 3.95 & 2,6 & 3.27 \\
\hline Presentation technique & 4 & 3 & \\
\hline Serving support & 3.8 & 2,4 & \\
\hline Presentation of learning & 4 & 2 & \\
\hline Coherence and sequence of thought & 4 & 3 & \\
\hline Aspects of Language Eligibility & 3.8 & 3,2 & 3.5 \\
\hline Straightforward & 4 & 4 & \\
\hline Communicative & 4 & 3 & \\
\hline Diagnosis and interactive & 4 & 3 & \\
\hline Conformity with development & 3 & 3 & \\
\hline Compliance with language rules & 4 & 3 & \\
\hline Aspects of Contextual Eligibility & 3.65 & 3 & 3.32 \\
\hline Contextual nature & 3.5 & 3 & \\
\hline Contextual component & 3.8 & 3 & \\
\hline Average & 3.75 & 2.86 & $\begin{array}{c}3.30 \\
\text { (Very good) }\end{array}$ \\
\hline
\end{tabular}

Table 4.Results of trials of respondents on the Botting Macca application for early detection and education of potential obesity

\begin{tabular}{|c|c|c|c|c|c|c|c|c|c|c|}
\hline User & I & II & III & IV & $\mathrm{V}$ & VI & VII & VIII & IX & $\mathrm{X}$ \\
\hline Interest & 3.66 & 3.16 & 3.16 & 3.83 & 3.83 & 4 & 3.5 & 4 & 3.5 & 3.66 \\
\hline Theory & 3.66 & 3.5 & 3.16 & 4 & 3.33 & 4 & 3.66 & 4 & 3.5 & 3.83 \\
\hline Language & 3.66 & 3 & 4 & 3.33 & 3.66 & 3.66 & 3.66 & 4 & 3.33 & 3.66 \\
\hline \multicolumn{5}{|c|}{ Component } & \multicolumn{6}{|c|}{ Average value } \\
\hline \multicolumn{5}{|c|}{ Interest } & \multicolumn{6}{|c|}{3.63} \\
\hline \multicolumn{5}{|c|}{ Theory } & \multicolumn{6}{|c|}{3.67} \\
\hline \multicolumn{5}{|c|}{ Language } & \multicolumn{6}{|c|}{3,6} \\
\hline \multicolumn{5}{|c|}{ Average } & \multicolumn{6}{|c|}{$\begin{array}{c}3.63 \\
\text { (Very good) }\end{array}$} \\
\hline
\end{tabular}




\subsection{Large Sample Trials}

Table 5 shows normal and overweight and obese respondents who are mostly at the age of $20-30$ with $90 \%$ or 18 respondents in the experimental group (given the Botting Macca application) and $100 \%$ or 20 respondents in the control group (given print media). The respondents in the two groups mostly work in private sector with 10 respondents $(50 \%)$ in the experimental group and 15 respondents $(75 \%)$ in the control group. Based on the respondents' mid-upper arm circumferences (MUAC) 9 respondents $(45 \%)$ in the experimental group were $\geq 23.5$ $\mathrm{cm}-25 \mathrm{~cm}$ of MUAC and 11 respondents $(55 \%)$ were $\geq 25.5 \mathrm{~cm}$ of MUAC. Meanwhile, 7 respondents $(35 \%)$ print media were $\geq 23.5 \mathrm{~cm}-25 \mathrm{~cm}$ of MUAC and 13 respondents $(65 \%)$ were $\geq 25.5 \mathrm{~cm}$ of MUAC in the control group.

Table 5. Description of Characteristics

\begin{tabular}{|c|c|c|c|c|c|c|c|c|}
\hline \multirow{3}{*}{$\frac{\text { Variable }}{\text { Age }}$} & \multicolumn{8}{|c|}{ Botting Macca Application } \\
\hline & \multicolumn{2}{|c|}{ Normal } & \multicolumn{2}{|c|}{ Overweight } & \multicolumn{2}{|c|}{ Obesity } & \multicolumn{2}{|c|}{ Total } \\
\hline & $\mathbf{n}$ & $\%$ & n & $\%$ & $\mathbf{n}$ & $\%$ & $\mathbf{n}$ & $\%$ \\
\hline$\leq 19$ years & 1 & $5 \%$ & - & - & 1 & $5 \%$ & 2 & $10 \%$ \\
\hline $20-30$ years & 6 & $30 \%$ & 6 & $30 \%$ & 6 & $30 \%$ & 18 & $90 \%$ \\
\hline$\geq 30$ years & - & - & - & - & - & - & - & - \\
\hline \multirow[t]{2}{*}{ Total } & & & & & & & 20 & $100 \%$ \\
\hline & \multicolumn{8}{|c|}{ Media Print } \\
\hline$\leq 19$ years & - & - & - & - & - & - & - & - \\
\hline 20-30 years & 8 & $40 \%$ & 7 & $35 \%$ & 5 & $25 \%$ & 20 & $100 \%$ \\
\hline$\geq 30$ years & - & - & - & - & - & - & - & - \\
\hline \multirow{2}{*}{ Total } & & & & & & & 20 & $100 \%$ \\
\hline & \multicolumn{8}{|c|}{ Botting Macca Application } \\
\hline \multirow{2}{*}{ Profession } & \multicolumn{2}{|c|}{ Normal } & \multicolumn{2}{|c|}{ Overweight } & \multicolumn{2}{|c|}{ Obesity } & \multicolumn{2}{|c|}{ Total } \\
\hline & $\mathbf{n}$ & $\%$ & n & $\%$ & $\mathbf{n}$ & $\%$ & $\mathbf{n}$ & $\%$ \\
\hline IRT & 1 & $5 \%$ & - & - & - & - & 1 & $5 \%$ \\
\hline entrepreneur & - & - & - & - & - & - & - & - \\
\hline Private & 2 & $10 \%$ & 4 & $20 \%$ & 4 & $20 \%$ & 10 & $50 \%$ \\
\hline PNS / Honorary & 1 & $5 \%$ & - & - & 2 & $10 \%$ & 3 & $15 \%$ \\
\hline Work / other & 3 & $15 \%$ & 2 & $10 \%$ & 1 & $5 \%$ & 6 & $30 \%$ \\
\hline \multirow[t]{2}{*}{ Total } & & & & & & & 20 & $100 \%$ \\
\hline & \multicolumn{8}{|c|}{ Media Print } \\
\hline IRT & - & - & - & - & - & - & - & - \\
\hline entrepreneur & - & - & - & - & - & - & - & - \\
\hline Private & 6 & $30 \%$ & 6 & $30 \%$ & 3 & $15 \%$ & 15 & $75 \%$ \\
\hline PNS / Honorary & 2 & $10 \%$ & 1 & $5 \%$ & 2 & $10 \%$ & 5 & $25 \%$ \\
\hline Work / other & - & - & - & - & - & - & - & - \\
\hline Total & & & & & & & 20 & $100 \%$ \\
\hline \multirow{3}{*}{$\begin{array}{c}\text { Upper Arm } \\
\text { Circumference (LILA) }\end{array}$} & \multicolumn{8}{|c|}{ Botting Macca Application } \\
\hline & \multicolumn{2}{|c|}{ Normal } & \multicolumn{2}{|c|}{ Overweight } & \multicolumn{2}{|c|}{ Obesity } & \multicolumn{2}{|c|}{ Total } \\
\hline & $\mathbf{n}$ & $\%$ & $\mathbf{n}$ & $\%$ & $\mathbf{n}$ & $\%$ & $\mathbf{n}$ & $\%$ \\
\hline$<23.5 \mathrm{~cm}$ & - & - & - & - & - & - & - & - \\
\hline$\geq 23.5 \mathrm{~cm}-25 \mathrm{~cm}$ & 7 & $35 \%$ & 2 & $10 \%$ & - & - & 9 & $45 \%$ \\
\hline$\geq 25.5 \mathrm{~cm}$ & - & - & 4 & $20 \%$ & 7 & $35 \%$ & 11 & $55 \%$ \\
\hline \multirow[t]{2}{*}{ Total } & & & & & & & 20 & $100 \%$ \\
\hline & \multicolumn{8}{|c|}{ Media Print } \\
\hline$<23.5 \mathrm{~cm}$ & - & - & - & - & - & - & - & - \\
\hline$\geq 23.5 \mathrm{~cm}-25 \mathrm{~cm}$ & 5 & $25 \%$ & 2 & $10 \%$ & - & - & 7 & $35 \%$ \\
\hline$\geq 25.5 \mathrm{~cm}$ & 3 & $15 \%$ & 5 & $25 \%$ & 5 & $25 \%$ & 13 & $65 \%$ \\
\hline Total & & & & & & & 20 & $100 \%$ \\
\hline
\end{tabular}

The average pre-test and post-test results for early detection of potential obesity are shown in Table 6 . The respondents' body weight and abdominal circumference in the experimental group decreased while in the control group print media increased. Besides, the respondents' height in both groups was stable. It implies that the Botting Macca application can be used for early detection of potential obesity and as a tool to help weight loss and reduction of abdominal circumference for brides. 
Table 6. Average Pre-Test and Post-Test Results for Early Detection of Potential Obesity

\begin{tabular}{ccccccc}
\hline \multirow{2}{*}{ Item } & \multicolumn{3}{c}{ Control (Print) } & \multicolumn{3}{c}{$\begin{array}{c}\text { Experiment } \\
\text { Botting Macca Application) }\end{array}$} \\
\cline { 2 - 7 } & Pre - Test & Post - Test & $N$ & Pre - Test & Post - Test & $N$ \\
\hline BB (kg) & 63.90 & 64.80 & 20 & 62.65 & 59.95 & 20 \\
TB (cm) & 156.90 & 156.90 & 20 & 156.75 & 156.75 & 20 \\
Abdomen (cm) & 76.35 & 76.90 & 20 & 75.60 & 74.60 & 20 \\
\hline
\end{tabular}

Table 7 shows the pre and posttest results of education of potential obesity monitoring. Seven respondents $(35 \%)$ were categorized obese and after using the Botting Macca application the number of obese respondents decreased by $10 \%$ ( 2 respondents). It implies that the Botting Macca application can be further developed to provide overweight and obesity education for prospective brides.

Table 7. Results of Pre-Test and Post-Test Monitoring of Potential ObesityEducation

\begin{tabular}{ccccccccc}
\hline \multirow{2}{*}{ Category } & \multicolumn{3}{c}{ Control (Print Out) } & \multicolumn{3}{c}{$\begin{array}{c}\text { Experiment } \\
\text { (Macca Botting Application) }\end{array}$} \\
\cline { 2 - 9 } & \multicolumn{2}{c}{ Pre - Test } & \multicolumn{2}{c}{ Post - Test } & \multicolumn{2}{c}{ Pre - Test } & \multicolumn{2}{c}{ Post - Test } \\
\cline { 2 - 9 } & Score & $\mathbf{( \% )}$ & Score & $\mathbf{( \% )}$ & Score & $\mathbf{( \% )}$ & Score & $(\%)$ \\
\hline Obesity & $\mathbf{5}$ & $\mathbf{2 5} \%$ & $\mathbf{8}$ & $\mathbf{4 0 \%}$ & $\mathbf{7}$ & $\mathbf{3 5 \%}$ & $\mathbf{2}$ & $\mathbf{1 0 \%}$ \\
Overweight & $\mathbf{7}$ & $\mathbf{3 5 \%}$ & $\mathbf{9}$ & $\mathbf{4 5 \%}$ & $\mathbf{6}$ & $\mathbf{3 0 \%}$ & $\mathbf{5}$ & $\mathbf{2 5 \%}$ \\
Normal & $\mathbf{8}$ & $\mathbf{4 0 \%}$ & $\mathbf{3}$ & $\mathbf{1 5 \%}$ & $\mathbf{7}$ & $\mathbf{3 5 \%}$ & $\mathbf{1 3}$ & $\mathbf{6 5 \%}$ \\
\hline amount & $\mathbf{2 0}$ & $\mathbf{1 0 0} \%$ & $\mathbf{2 0}$ & $\mathbf{1 0 0} \%$ & $\mathbf{2 0}$ & $\mathbf{1 0 0} \%$ & $\mathbf{2 0}$ & $\mathbf{1 0 0 \%}$
\end{tabular}

The result of data analysis by using the Man-Whitney statistical test was shown in Table 8 . The result obtained p-value $0.001<\mathrm{p}$ value 0.05 with Ho was rejected and Ha was accepted meaning there was a difference in the effect of using the Botting Macca application for early detection and education of potential obesity with print media. The results of the mean ranks of the experimental group and control group were 26.05 and 14.95 respectively.

Table 8. The Mann-Whitney test

\begin{tabular}{cccc}
\hline Media & n & Mean Rank & P-Value \\
\hline Botting Macca Application & 20 & 26.05 & \multirow{2}{*}{0.001} \\
Print Media & 20 & 14.95 & \\
\hline
\end{tabular}

\section{Discussion}

The android-based Botting Macca application can be used and developed as a tool for early detection in terms of body weight, height, and abdominal circumference as well as education for potential obesity in terms of food menu selection and physical activity for prospective brides.

The Botting Macca application has some menus in it. The users would find a login menu consisting of a user and a password as the initial screen shown in Figure 1. After logging in, the user would get several advanced features, such as profiles, instructions for use, early detection features, results of early detection, and educational monitoring adjusted from early detection results. Users also can see a logout menu if they want to exit the application at any time. All of these features are shown in Figure 2. Figure 3 describes the items of early detection from the early detection feature, recommendation, and education that the application suggests to users.

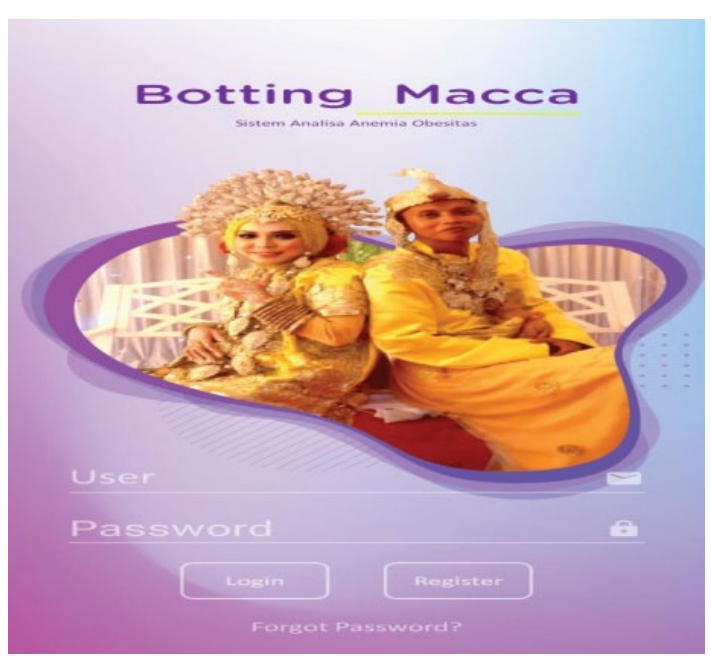

Figure 1: Login Features Menu

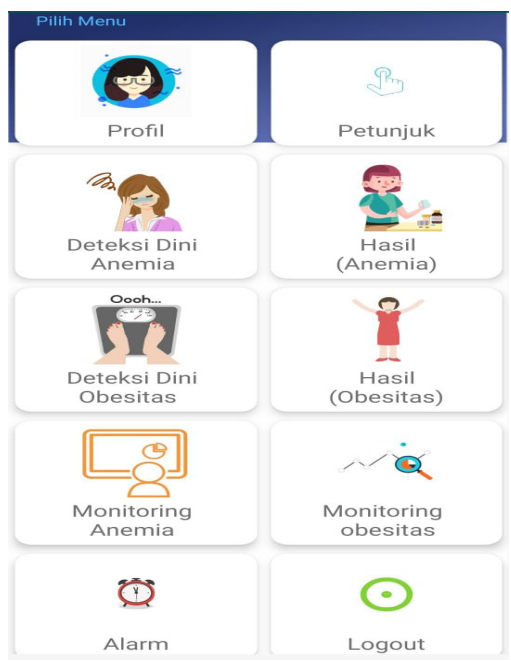

Figure 2: Advanced Features Menu 

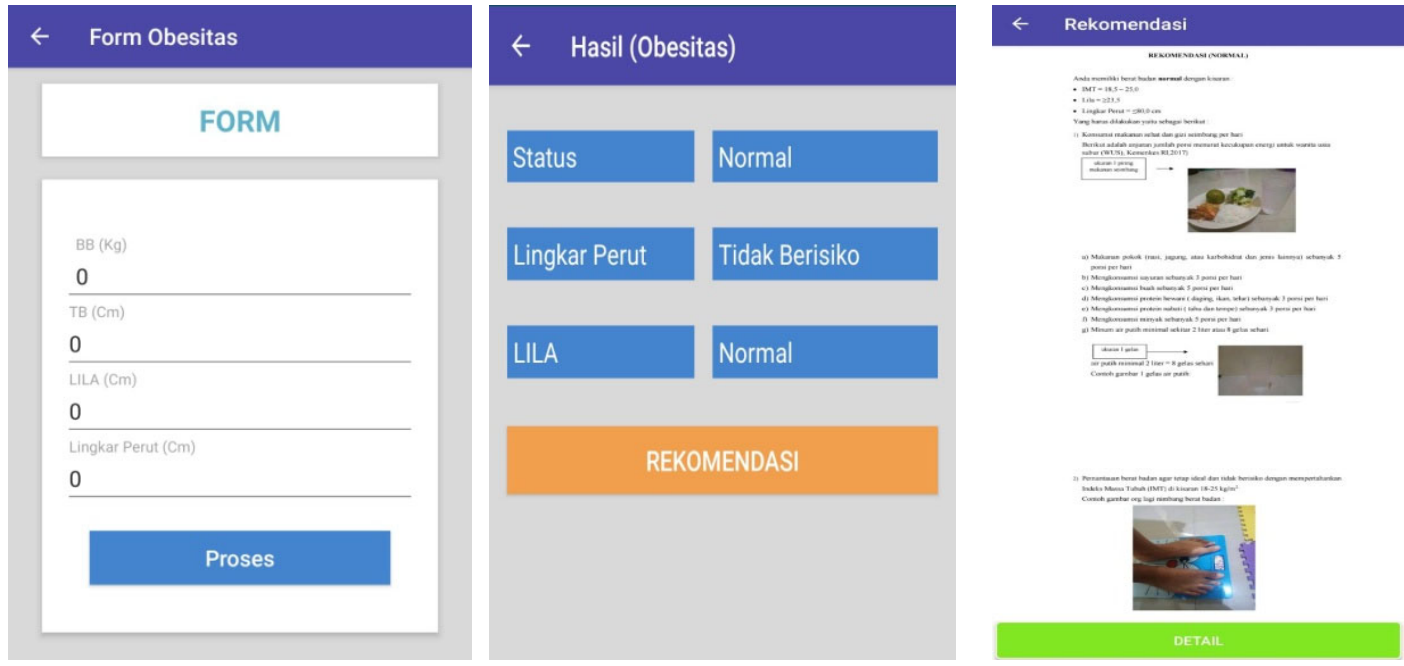

Figure 3: Early Detection Features Menu, Result Features, and Recommendations

The use of the smartphone-based application can be an important component in preventing and reducing cases of being overweight or obese for prospective brides (Schoeppe et al. 2016; Survey and Aljuraiban 2019; Kliemann et al. 2019). This is in line with another research (Matthews et al. 2017) developing an application and web-based namely "HelpMeDoIt!" for adult respondents with obese conditions so that they can obtain social support and build their awareness of the detection results generated by the application.

According to the results of the validation test by media and material experts and small sample trials, they suggest that the assessment results from material and media experts and a small sample trial show an average score of 3.30 (see Table 2,3.25 (see Table 3), and 3.63 (see Table 4) respectively. These numbers are categorized into very good, good, and very good category The criteria for the assessment results matched the results of the study so that the product was very feasible and could be used without revision (Amelia et al. 2020).

This study described the characteristics of the respondents in two groups (Table 5) There were $29.4 \%$ of women aged $19-55$ years observing at risk for obesity and most of them had a sedentary lifestyle or light activity. Examples of a sedentary lifestyle are students (not working), housewive, entrepreneurs/traders, workers in private sector, etc) (JY Lee et al. 2019). The use of MUAC in this study is in line with the research conducted by Shane HR and Pasiak (2016) stating that there is a relationship between upper arm circumference and obesity. This study obtained a spearman correlation value of 0.7111 meaning that MUACis strongly associated with obesity and body mass index (BMI). If a woman's MUAC is more than the normal limit of $25.5 \mathrm{~cm}$, she is at risk of being overweight and obese.

Several changes occurred in both experimental and control groups during the study. The first change is related to weight loss. Twenty respondents in the experimental group with Botting Macca application had an average body weight of $62.65 \mathrm{~kg}$ and it significantly decreased for 4 weeks with an average of $59.95 \mathrm{~kg}$. On the other hand, 20 respondents in the control group with print media had an average body weight of $63.90 \mathrm{~kg}$, and it increased to 0.9 $\mathrm{kg}$ for 4 weeks. The second change is related to the abdominal circumference. The experimental group experienced an average of $1 \mathrm{~cm}$ decrease of abdominal circumference from $75.60 \mathrm{~cm}$ to $74.60 \mathrm{~cm}$ whereas an increase of 0.55 $\mathrm{cm}$ from $76.35 \mathrm{~cm}$ to $76.90 \mathrm{~cm}$ was experienced by 20 respondents in the control group for 4 weeks (see Table 6). The results of this study were in line with the previous one testing an application called Track Unit to 20 overweight and obese respondents for 4 weeks. The findings show the respondents' body weight decreased with an average median value of $-2.7 \mathrm{~kg}$ (Buchan and Morgan 2019). Another result from a previous study in Seoul reveals that there was a reduction of body fat $-6.0-5.4 \%$. This study used an application namely NOOM for 15 weeks to 104 respondents aged between 20-60 with overweight and obese conditions, The reduction of body fat affected the decrease of the abdominal circumference by $1 \mathrm{~cm}$ or $-3.4 \%-2.7 \mathrm{~kg}$ over 6 weeks (D. Lee and Michaelides 2017). The above results suggest that the respondents experiencing body weight changes in the control group were mostly at risk based on BMI categories (Ministry of Health of the Republic Indonesia, 2017). Some of them were from rural areas (Lancet 2015). A healthy lifestyle (Nurwanti et al. 2018) and education for brides and grooms are important to prevent overweight and obesity (Mahmudiono et al. 2016). The third change is related to body height. There was no significant change in body height for both groups, however. This study result was in line with another research result saying that the given intervention does not affect height, but it affects body weight based on the BMI calculation of respondents (2018 Sofa).

Table 7 shows the results of the pre-and post-test of education of potential obesity. There was a reduction in the number of respondents categorized into obese and overweight after using the application. The reduction 
occurred from the first week until the fourth week of monitoring was from $35 \%$ ( 7 respondents) to $10 \%$ ( 2 respondents) in the obese category and from $30 \%$ (6 respondents) to $25 \%$ (5 respondents) in the overweight category. The changes in these categories gave a positive impact on the increase of normal category from $35 \%$ ( 7 respondents) to $65 \%$ (13 respondents) meaning that there was a $30 \%$ increase in the normal category. The change occurred because most respondents understood their condition. They regularly checked themselves and the education given was based on the explanation in the application. The changes in terms of lifestyle (Pengpid and Peltzer 2017) such as adapting good sleep habit, doing physical activity (Nurwanti et al. 2018), diet (Khusun and Fahmida 2016), and more understanding in nutritional balance were carried out by most respondents (Gerson et al 2011) Any increase in respondents' knowledge about a healthy life will make their life better (Mahmudiono et al. 2016) as they know the impact of adopting a healthy life (Susiyadi 2016) for now (Dune, Barnes, and Marsh 2014) and the future (Soltani et al. 2017). The results of this study are in line with the research results of 20 female respondents with overweight and obese categories. The results show changes every week. The initial median BMI was $32 \mathrm{~kg} / \mathrm{m} 2$ and it became $30.8 \mathrm{~kg} / \mathrm{m} 2$ for 4 weeks so that the intervention could affect the category of respondents (Buchan and Morgan 2019). The results of the study in the control group show 25\% (5 respondents) were categorized obese and then increased to $40 \%$ ( 8 respondents). Also, there was an increase of $10 \%$ from the initial value of $35 \%$ ( 7 respondents) to $45 \%$ ( 9 respondents) in the fourth week for the overweight category. Meanwhile, there was a decrease in the normal category from $40 \%$ ( 8 respondents) in the first week to $15 \%$ ( 3 respondents) in the fourth week. Hence, there was a decrease of $25 \%$ for 4 weeks (see Table 7). Based on the data collection, the respondents were in the normal category initially. (Oddo, Maehara, and Rah 2019), but they did not apply a healthy lifestyle (Pengpid and Peltzer 2017), and still lacked an understanding of the potential dangers of obesity that could threaten their future (Pengpid and Peltzer 2016). The results of this study were similar to another research using 2 methods, namely using an application using paper to rewrite what had been consumed for 24 hours ( $24 \mathrm{~h}$ food recall). The results of the study show that mean energy intake was $8854 \pm 2267$ and total mean fat intake was $34.0 \pm 6.2$ in the experimental group. On the other hand, mean energy intake and total mean fat intake was $9123 \pm 2337$ and $34.8 \pm 6.7$ respectively in the control group (Ambrosini et al. 2018)

The results of the statistical tests in Table 8 used the Mann-Whitney test with a p-value of $0.001<0.05$. This is in line with what has been said by Ambrosini et al. (2018) saying that there is a significant difference in the changes experiencing by the respondents in the obese category of the experimental group in terms of energy intake and total fat intake compared to those in the control group.

Instead of using print media, using the application eases the users to educate themselves. Various forms of application such as web-based and smartphone are proven to increase the effectiveness of health promotion (Granado-font et al. 2015). Studies on the use of media applications to solve overweight and obesity problems have been widely carried out to promote a healthy life (Schoeppe et al. 2016).

The use of the application makes it easier for public and medical personnel to control and reduce the number of overweight and obesity and other health problems (Amelia et al. 2020). Several policies in some countries have established countermeasures through surveys from the results of application assessments for some health problems (JY Lee et al. 2019).

The implication of this research is to facilitate early detection and help people in getting proper education that has been recommended by the application for prospective brides. The application is proven to change the respondents' attitudes and behavior towards overweight and obesity. Therefore, the use of the Botting Macca application is considered feasible and can be developed as an educational media. The health education through media applications helps women with overweight and obesity categories to lose weight (D. Lee and Michaelides 2017), change their lifestyle (Duncan et al. 2018) and at the same time provide social support for the health problems they face (Matthews et al. 2017)

\section{Conclusion}

The development of an android-based application product called Botting Macca was suitable for use without any revision and could be developed as a medium for early detection and education of potential obesity for prospective brides. The product was developed based on the assessment results from media and material experts as well as small sample trials including the components of application size, cover design, application content design, aspects of the feasibility of the content, presentation, language and context, components of interest, and material. Large sample trials of prospective brides using the Botting Macca application were carried out as early detection and education of potential obesity affecting body weight and abdominal circumference while the height did not change significantly.

The development for further research is expected to develop a component of automatic calorie counting by using food photos equipped with a consultation sheet or consultation number which could describe the kinds of food calories to eat. Besides, a feature of the walking tracker as many respondents prefer doing morning and evening walks as alternative options for physical activity in the Botting Macca application for early detection and education of potential obesity in prospective brides. 


\section{Reference}

Afshin, Ashkan et al. 2016. "Information Technology and Lifestyle : A Systematic Evaluation of."

Ambrosini, Gina L et al. 2018. "Feasibility of a Commercial Smartphone Application for Dietary Assessment in Epidemiological Research and Comparison with 24-H Dietary Recalls." : 1-10.

Amelia, Kiki et al. 2020. "A Digital Partograph Model As Learning Media For The Normal Childbirth Care." 24(4): 5624-31.

Beleigoli, Alline Maria et al. 2018. "Online Platform for Healthy Weight Loss in Adults with Overweight and Obesity - the 'POEmaS' Project : A Randomized Controlled Trial.” : 1-7.

Buchan, Kelly, and Heather M Morgan. 2019. "Using the Onitor ${ }^{\circledR}$ Track for Weight Loss : A Mixed Methods Study among Overweight and Obese Women."

Duncan, Mitch J et al. 2018. "Examining the Efficacy of a Multicomponent M-Health Physical Activity, Diet and Sleep Intervention for Weight Loss in Overweight and Obese Adults: Randomised Controlled Trial Protocol." : 1-14.

Dune, Tanaka J, Randall B Barnes, and Erica E Marsh. 2014. "Reproductive Health Outcomes." 207(6): 1-14.

Dunn, Caroline Glagola, Gabrielle M Turner-mcgrievy, Sara Wilcox, and Brent Hutto. 2019. "Dietary SelfMonitoring Through Calorie Tracking but Not Through a Digital Photography\&nbsp;App Is Associated with Significant\&nbsp;Weight Loss: The 2SMART Pilot Study-A 6-Month Randomized Trial." Journal of the Academy of Nutrition and Dietetics: $1-8$. https://doi.org/10.1016/j.jand.2019.03.013.

Foley, Perry et al. 2016. "Track: A Randomized Controlled Trial of a Digital Health Obesity Treatment Intervention for Medically Vulnerable Primary Care Patients." Contemporary Clinical Trials. http://dx.doi.org/10.1016/j.cct.2016.03.006.

Fransen, Mirjam P et al. 2018. "Preconception Counselling for Low Health Literate Women : An Exploration of Determinants in the Netherlands." : 1-12.

Gerson et all. 2011. "The Role of Fat Mass Index in Determining Obesity." 22(5): 639-47.

Granado-font, Esther et al. 2015. "Effectiveness of a Smartphone Application and Wearable Device for Weight Loss in Overweight or Obese Primary Care Patients : Protocol for a Randomised Controlled Trial." BMC Public Health: 2-7. http://dx.doi.org/10.1186/s12889-015-1845-8.

Hernandez, Reyes et al. 2020. "Effectiveness of PUSH Notifications from a Mobile App for Improving the Body Composition of Overweight or Obese Women : A Protocol of a Three-Armed Randomized Controlled Trial.” : $1-10$.

Huang, Zhilian et al. 2019. "Medication Management Support in Diabetes : A Systematic Assessment of Diabetes Self-Management Apps.": 1-12.

Hutchesson, Melinda J et al. 2016. "Be Positive Be Health E : Development and Implementation of a Targeted EHealth Weight Loss Program for Young Women." 22(6): 519-28.

Kementrian Kesehatan RI. 2017. "HASIL PEMANTAUAN STATUS GIZI ( PSG ) TAHUN 2017."

Khusun, Helda, and Umi Fahmida. 2016. "Dietary Patterns of Obese and Normal-Weight Women of Reproductive Age in Urban Slum Areas in Central Jakarta." 116.

Kliemann, Nathalie, Helen Croker, Fiona Johnson, and Rebecca J Beeken. 2019. "Development of the Top Tips Habit-Based Weight Loss App and Preliminary Indications of Its Usage , Effectiveness , and Acceptability : Mixed-Methods Pilot Study Corresponding Author :" 7.

Lancet. 2015. "Europe PMC Funders Group Global, Regional and National Prevalence of Overweight and Obesity in Children and Adults 1980-2013 : A Systematic Analysis." 384(9945): 766-81.

Lee, Dong-hwa, and Andreas Michaelides. 2017. "Effectiveness of a Smartphone Application for the Management of Metabolic Syndrome Components Focusing on Weight Loss :" 15(9): 465-73.

Lee, Ju Yeon et al. 2019. "Development and Usability of a Life-Logging Behavior Monitoring Application for Obese Patients." : 194-202.

Leech, Tamara G J, and Janice Johnson. 2012. "Risky Sexual Behavior : A Race-Specific Social Consequence of Obesity." 1980: 41-52.

Mahmudiono, Trias et al. 2016. "The Effectiveness of Nutrition Education for Overweight / Obese Mothers with Stunted Children ( NEO-MOM ) in Reducing the Double Burden of Malnutrition in Indonesia: Study Protocol for a Randomized Controlled Trial." BMC Public Health. http://dx.doi.org/10.1186/s12889-0163155-1.

Matthews, Lynsay et al. 2017. "Study Protocol for the 'HelpMeDoIt!' Randomised Controlled Feasibility Trial : An App, Web and Social Support-Based Weight Loss Intervention for Adults with Obesity."

Mooyaart, Jarl E, Aart C Liefbroer, and Francesco C Billari. 2019. "Becoming Obese in Young Adulthood: The Role of Career-Family Pathways in the Transition to Adulthood for Men and Women." : 1-12.

Nurwanti, Esti et al. 2018. "Roles of Sedentary Behaviors and Unhealthy Foods in Increasing the Obesity Risk in Adult Men and."

Oddo, Vanessa M, Masumi Maehara, and Jee Hyun Rah. 2019. “Overweight in Indonesia : An Observational Study 
of Trends and Risk Factors among Adults and Children."

Pegington, Mary, David P French, and Michelle N Harvie. 2020. "Why Young Women Gain Weight : A Narrative Review of Influencing Factors and Possible Solutions.” (September 2019): 1-15.

Pengpid, Supa, and Karl Peltzer. 2016. "Associations between Behavioural Risk Factors and Overweight and Obesity among Adults in Population-Based Samples from 31 Countries." Obesity Research \& Clinical Practice: 1-9. http://dx.doi.org/10.1016/j.orcp.2016.08.001.

. 2017. "The Prevalence of Underweight, Overweight / Obesity and Their Related Lifestyle Factors in Indonesia , 2014 - 2015.” 4(October): 633-49.

Pujilestari, Cahya Utamie, Lennarth Nyström, Margareta Norberg, and Nawi Ng. 2019. "Waist Circumference and All-Cause Mortality among Older Adults in Rural Indonesia." : 1-13.

Risk, N C D, and Factor Collaboration. 2017. "Articles Worldwide Trends in Body-Mass Index , Underweight , Overweight , and Obesity from 1975 to 2016 : A Pooled Analysis of 2416 Population-Based Measurement Studies in $128 \cdot 9$ Million Children , Adolescents , and Adults." 6736(17): 1-16.

Rosengren, A et al. 2015. "Psychosocial Factors and Obesity in 17 High- , Middle- and Low-Income Countries : The Prospective Urban Rural Epidemiologic Study.” 39(8): 1217-23. http://dx.doi.org/10.1038/ijo.2015.48

Schoeppe, Stephanie et al. 2016. "Efficacy of Interventions That Use Apps to Improve Diet, Physical Activity and Sedentary Behaviour: A Systematic Review." International Journal of Behavioral Nutrition and Physical Activity. http://dx.doi.org/10.1186/s12966-016-0454-y.

Sebastian, Miguel San. 2020. "Societal Risk Factors for Overweight and Obesity in Women in Zimbabwe: A Cross- Sectional Study." : 1-8.

Shane H R, and Taufiq F Pasiak. 2016. "Hubungan Lingkar Lengan Atas Dengan Obesitas Pada Mahasiswa Kandidat Skripsi Fakultas Kedokteran Universitas Sam Ratulangi Manado Obesitas Didefinisikan Sebagai Akumulasi Lemak Abnormal Atau Berlebihan Yang Dapat Obesitas Merupakan Faktor Predisposisi Unt." 4.

Short, Camille E, Amy Finlay, Ilea Sanders, and Carol Maher. 2018. "Development and Pilot Evaluation of a Clinic-Based mHealth App Referral Service to Support Adult Cancer Survivors Increase Their Participation in Physical Activity Using Publicly Available Mobile Apps." : 1-11.

Sofa, Ira Maya. 2018. "Kejadian Obesitas , Obesitas Sentral, Dan Kelebihan Lemak Viseral Pada Lansia Wanita The Incidence of Obesity , Central Obesity , and Excessive Visceral Fat among Elderly Women.” : 228-36.

Soltani, Hora et al. 2017. "Pre-Pregnancy Body Mass Index and Gestational Weight Gain and Their Effects on Pregnancy and Birth Outcomes : A Cohort Study in West Sumatra, Indonesia." : 1-12.

Survey, A Web-based, and Ghadeer S Aljuraiban. 2019. "Use of Weight-Management Mobile Phone Apps in Saudi Arabia : Corresponding Author :" 7: 1-11.

Susiyadi. 2016. "PENGARUH OBESITAS TERHADAP DISFUNGSI SEKSUAL WANITA DI KECAMATAN PATIKRAJA BANYUMAS Susiyadi 1, Siti Rokhayah 1 1.” 14(3): 24-29.

Wang, Rui et al. 2016. "Prevalence of Overweight and Obesity and Some Associated Factors among Adult Residents of Northeast China : A Cross-Sectional Study." : 1-9. 